\title{
ANALISIS UNSUR INTRIN SIK KITAB “BARZANJI” KARYA JA'FAR AL BARZANJI (NASKAH DITERJEMAHAN OLEH ABU AHMAD NADJIEH) PERSPEKTIF PONDOK PESANTEREN ITTIHADIL UMMAH KARANG ANYAR MATARAM
}

\author{
Najamuddin \\ Dosen TBI FTK UIN Mataranm \\ najamuddin577@yahoo.co.id
}

\begin{abstract}
Abstrak: "Barzanji" merupakan aktivitas pembacaan riwayat Nabi Muhammad SAW. Kitab ini merupakankarya sastra karena lebih menonjolkan aspek keindahan bahasa (sastra). Kitab ini ada dua macam yang satu dalam bentuk prosa dan lainnya dalam bentuk puisi. Isi keduanya mengkisahkan riwayat kehidupan Nabi Muhammad SAW terutama dalam bentuk peristiwa kelahirannya.
\end{abstract}

Penelitian ini berdasarkan pertimbangan bahwa naskah "Barzanji” Karya Syekh Ja'far Al-Barzanji Husin bin Abdul Karim belum dideskripsikan pada aspek intrinsiknya. Dengan demikian, diperlukan penelitian secara spesifik, yang membentuk unsur intrinsik dari Naskah "Barzanji” seperti Plot,Setting, Point of View (sudut pandang), Character (Penokohan), Style (Gaya), Theme (Tema) dan Atmosphere (Suasana) Perspektif Pondok Pesanteren Ittihadil UmmahKarang Anyar Mataram”

Membaca kitab Barzanji sangat berguna dan bermanfaat bagi kita, dan sangat disayangkan apabila tidak dilantunkan oleh generasi selanjutnya. Oleh karena itu harus tetap dilestarikan. Usaha melestarikan membaca naskah Barzanji sangatlah perlu terus dilakukan pengembangan, dokumenas, dan penelitian lebih lanjut. Selanjutnya, sebagai usaya untuk masyarakat, membaca Barzanji terus lantunkan bukan saja pada acara-acara keagamaan tetapi juga untuk menambahwawasandan pengetahuanterkaitnilai agama, kehidupan sosial, dan lainnya.

Kata Kunci: Unsur Intrinsik, Kitab Barzanji, Perspektif 


\section{A. PENDAHUUAN}

Bahasa adalah sebagian dari budaya. Bahasa menjadi sesuatu yang sangat penting karena mencerminkan budaya. Bahasa dan budaya memang merupakan hal yang padu sehingga dengan mengamati hal-hal dalam bahasa misalnya cara berbahasa akan diperoleh gambaran mengenai budaya pemilik bahasa tersebut. Di samping itu, dengan berbahasa dapat dijalin hubungan sosial. ${ }^{1}$

Hutomo mengatakan bahwa sastra lisan adalah kesusastraan yang mencakup ekspresi kesusastraan warga suatu kebudayaan yang disebarkan secara lisan (dari mulut ke mulut). Perlu diketahui bahwa sastra lisan dalam masyarakat tradisional bersifat komunal, artinya milik bersarna (rakyat). Dengan demikian, sastra lisan disebut folks literature atau sastra rakyat. ${ }^{2}$

Dikatakan oleh Hutomo bahwa salah satu ciri sastra lisan adalah penyebarannya melalui mulut ke mulut. Maksudnya, ekspresi budaya yang disebarkan, baik dari segi waktu maupun ruang melalui mulut. Jadi, tidak mustahil pada suatu saat sastra lisan, khususnya "Barzanji” akan hilang tanpa bekas. Oleh karena perlu dilakukan usaha pelestarian, baik dari segi penelitian maupun pendeskripsian terhadap sastra lisan tersebut agar pewarisannya bisa terjamin kepada generasi berikutnya. ${ }^{3}$

Karya sastra tidak hanya dinikmati sebagai bentuk seni antara teks,namunlebih dari itu, ia menjadi bagian dari ungkapan masyarakat masih menjaga tradisi sastra lisannya di tengah-tengah serbuaan budaya populer.

Menurut As'ad Al-Tabi'in Al-Andalasi, "Barzanji” merupakan kegiatan pembacaan riwayat Nabi Muhammad SAW. Kitab Al-Barzanji ditulis dengan tujuan untuk meningkatkan kecintaan kepada Rasulullah SAW dan meningkatkan gairah umat. Dalam kitab itu riwayat Nabi saw dilukiskan dengan bahasa yang indah dalam bentuk puisi dan prosa (nasr) dan kasidah yang sangat menarik. Dalam Barzanji diceritakan bahwa kelahiran kekasih Allah ini ditandai dengan banyak peristiwa ajaib yang terjadi saat itu, sebagai genderang tentang kenabiannya dan pemberitahuan bahwa Nabi Muhammad adalah pilihan Allah. Kitabini merupakan karya sastra karena lebih menonjolkan aspek keindahan bahasa (sastra). Kitab ini ada dua macam yang satu dalam bentuk prosa dan lainnya dalam bentuk puisi. Isinya samasama menceritakan riwayat hidup Nabi Muhammad SAW terutama dalam bentuk peristiwa kelahirannya.

1 Sherzer, Joel. Explaination in Ethnography of Speaking. (Cambridge University, 1979), h. 7.

2 Ibid., h. 7

3 Hutomo, Suripan Sadi. Mutiara yang Terlupakan. Pengantar Studi Sastra Lisan. (Jawa Timur : Hiski, 1991. ), h. 3.

4 https://www.facebook.com/notes/mohammad-luqman-firmansyah/biografi-pengarang-kitab-maulidbarzanji-syaikh-jafar-al-barzanji/10150089501780135/ (Dikutip pada tanggal 4-11-2018). 
Lantuan "Barzanji" umumnya dibacakan dalam sebuah acara tertentu bagi umat Islam seperti yang telah dipaparkan sebelumnya, namun ini bukan merupakan suatu keharusan karena tidak ada dasar ataupun keterangan yang mewajibkan. Pada dasarnyatujuan sangat baik, yaitu memberi apresiasi kepada Nabi SAW dengan cara membacakan riwayat hidupnya. Kita sebagai generasi selanjutnyabukan saja sekedar membacanya tetapi lebih dari itu artinya kita dapat mengambil makna dan pelajaran yang sangat berharga dari kehidupan beliau.

Asal-usul "Barzanji" yang dikutip dariAs'ad Al-Tabi'in Al-Andalasi. Kata "Barzanji" dalam kamus besar bahasa Indonesia diartikan sebagai isi bacaan pujipujian yang berisi riwayat Nabi Muhammad SAW, terkadang kita beranggapan baha awalan "ber" merupakan imbuhan. Padahal kata "Berzanji" berasal kata Al-Barzanji, nama belakang penulis prosa dan puisi yang terkenal yang mempunyai nama lengkap Ja'fa Al Barzanji. ${ }^{5}$

Syaikh Ja'far Al-Barzanji dilahirkan pada hari Kamis awal bulan Zulhijjah tahun 1126 di Madinah Al-Munawwaroh dan wafat pada hari Selasa, selepas Asar, 4 Sya'ban tahun 1177 H di Kota Madinah dan dimakamkan di Jannatul Baqi’, sebelah bawah maqam beliau dari kalangan anak-anak perempuan Junjungan Nabi saw.Sayyid Ja'far Al-Barzanji adalah seorang ulama' besar keturunan Nabi Muhammad saw dari keluarga Sa’adah Al Barzanji yang termasyur, berasal dari Barzanj di Irak. Datuk-datuk Sayyid Ja'far semuanya ulama terkemuka yang terkenal dengan ilmu dan amalnya, keutamaan dan keshalihannya. Beliau mempunyai sifat dan akhlak yang terpuji, jiwa yang bersih, sangat pemaaf dan pengampun, zuhud, amat berpegang dengan AlQuran dan Sunnah, wara', banyak berzikir, sentiasa bertafakkur, mendahului dalam membuat kebajikan bersedekah, dan pemurah. ${ }^{6}$

Kitab "Barzanji” terdiri dari dua bagian besar, yaitu Natsar dan Nadhom.Natsar berupa prosa liris yang menceritakan kehidupan Nabi maupun silsilah Beliau. Bagian ini terdiri dari 19 sub, sedangkan Nadhom terdiri dari 205 untaian syair. Bagian ini menyatu ke dalam 16 sub bagian.

Karya sastra lisan "Barzanji"dipilih sebagai objek penelitian. Pemilihan objek penelitian ini berdasarkan pertimbangan bahwa naskah "Barzanji" belum dideskripsikan pada aspekintrinsiknya. Dengan demikian, diperlukan penelitian secara spesifik, yang membentuk unsur intrinsik dari Naskah "Barzanji" seperti Plot,Setting, Point of View (sudut pandang), Character(Penokohan), Style(Gaya), Theme(Tema) dan Atmosphere(Suasana).Untuk memahami Naskah "Barzanji”, kita harus mengetahui isi yang ada dalam teks "Barzanji" dan seberapa jauh kita dapat memahaminya. Hal

5 Al-Andalasi, As'ad Al-Tabi’ in. 2014. Sejarah al-Barzanji dan Perkembangannya. (Dikutip di internet hari Senin tanggal 7 Maret 2016, a2dcollection.blogspot.co.id/2014/12/sejarah-al-barzanji-dan-perubahannya.HTML)

6 https: / / www.facebook.com/notes / mohammad-luqman-firmansyah/biografi-pengarangkitab-maulid-barzanji-syaikh-jafar-al-barzanji/ 10150089501780135 / (Dikutip pada tanggal 4-11-2018). 
ini tergantung pada seberapa jauh pemahaman kita terhadap Unsur Intrinsik yang ada dalam Naskah "Barzanji” Perspektif Pondok Pesanteren Ittihadil UmmahKarang Anyar Mataram dengan menarik inferensi unsur-unsur verbal dan nonverbal yang sudah di translitrasi dan diterjemahan sesuai dengan referensi yang peneliti gunakan "Barzanji” Karya Ja’fa Al Barzanji (Kitab diterjemahkan oleh Abu Ahmad Nadjieh) di terbitkan oleh Mutiara Ilmu Surabaya, Cetakan Pertama, Maret 2009/ Rabiul Awal $1430 \mathrm{H}$.

\section{B. PEMBAHASAN}

Memahami kitab "Barzanji”, penulis berupayamencermatinya secara berulangulang atau heuristik.Hal itu penting karena untukmemahami dan menghargai suatu teks, baik teks lisan, teks kuno, maupun teksmodern diperlukan penghayatan yang penuh dan terus- menerus. Penghayatan itu berkaitan dengan nilai keindahan yang terkandung dalarn teks (Hutomo,1999:11). ${ }^{7}$

Untuk menemukan nilai-nilai sosial yang terkandung di dalamnya dan menjelaskan hubungan antara segi bahasa dan fungsi artistik seorang pengarang. Di pihak lain, Teeuwmenyatakan bahwa stilistika, ilmu gaya bahasa, pada prinsipnya selalu meneliti pemakaian bahasa yang khas atau istimewa, yang merupakan ciri khas seorang penulis aliran sastra.Untuk memahami "Barzanji” ini diperlukan juga suatu proses pemahaman, yakni hermeneutik. Hermeneutik merupakan proses interpretasi teks karya sastra dalarn rangka menemukan unsur-unsur teks. Pada dasarnya hermeneutik berhubungan dengan bahasa. ${ }^{8}$

Mengingat Barzanji merupakan salah satu sastra lisan yang menggunakan bahasa Arab dan sudah diterjemahkan oleh Abu Ahmad Nadjieh, maka transkripsi Barzanji yang telah diterjemahkan tersebut dapat membantu peneliti mengkaji lebih jauh tentunya mengikuti prinsip "pemindahan secara setia" artinya semua ucapan dalarn Barzanji dipindahkan dalam bentuk tulisan, yakni keadaan teks agar tidak jauh berbeda dengan aslinya.

Produk sastra lisan Barzanji mencerminkan makna yang tersirat dalam konteks sosial dan budaya yang pada dasarnya tersimpan nilai-nilai kehidupan didalam ekspresi liriknya. Sejumlah nilai-nilai tersebut mengandung sejumlah makna yang mendalam yang dipresentasikan oleh pengguna kitab Barzanji, misalnya pada acara akad nikah, khitanan anak, acara peringatan kelahiran Nabi Muhammad S.A.W, dan menempati rumah baru.

Di bawah ini diberikan beberapa transkripsi sastra lisan "Barzanji" terkait inferensi unsur-unsur verbal dan nonverbal yang sudah ditranslitrasi dan diterjemahan

7 Hutomo. Mutiara yang Terlupakan., h. 11.

8 Teeuw. A. Sebuah Pengantar Sastra dan Ilmu Sastra. (Jakarta: Dunia Pustaka Jaya, 1984), h. 72. 
sesuai dengan referensi yang peneliti gunakan “Barzanji”Karya Ja’fa Al Barzanji (Kitab diterjemahkan oleh Abu Ahmad Nadjieh) di terbitkan oleh Mutiara Ilmu Surabaya, Cetakan Pertama, Maret 2009/ Rabiul Awal 1430 H.

\section{Plot (Alur)}

Plot adalah struktur gerak dalam cerita; pada prinsipnya bentuk karya sastra bergerak mulai dari permulaan (beginning), pertengahan(middle) dan akhir (ending), yang dalam dunia sastra lebih dikenal sebagai eksposisi, komplikasi, dan resolusi (atau denounment). ${ }^{9}$ Plot (Alur) merupakan kerangka dasar yang amat penting artinya bagaimana satu peristiwa mempunyai hubungan dengan peristiwa yang lain, bagaimana tokoh yang digambarkan dan berperan dalam peristiwa itu yang semuanya terikat dalam suatu kesatuan waktu.

Peneliti akan memaparkan plot (alur) Kitab Al-Barzanji mulai dari eksposisi,komplikasi, dan resolusiataudenounment. ${ }^{10}$ Jenis plot (alur) yang terbangun dalam kitab Al-barzanji ini adalah alur gabungan, dimana peristiwa-peristiwa pokok diutarakan, pembaca diajak mengenang peristiwa-peristiwa yang lampau,kemudian mengenang peristiwa pokok (dialami oleh tokoh utama) lagi. Kutipan plot (alur) dapat dipaparkan melalui beberapa bagian tahap-tahap plot (alur), seperti:

\section{a. Eksposisi}

Eksposisiadalah tahap permulaan yang mengatur gerak dan berkaitan dengan masalah-masalah waktu dan tempat. Dalam eksposisi ini diperkenalkan para tokoh pelaku kepada para pembaca, mencerminkan para tokoh pelaku, merencanakan konflik yang akan terjadi, dan sementara itu memberikan suatu indikasi. ${ }^{11}$

Kutipan eksposisi dilihat naskah "Al Barzanji”"yang diterjemahkan oleh Abu Ahmad Nadjieh pada BAB I halaman 5-9:

Pengarang Kitab Al-Barzanji yaitu Syekh Ja'far Al-Barzanji Husin bin Abdul Karim mengawali eksposisinya dengan kalimat shalawat dan salam kepada junjungan Nabi.

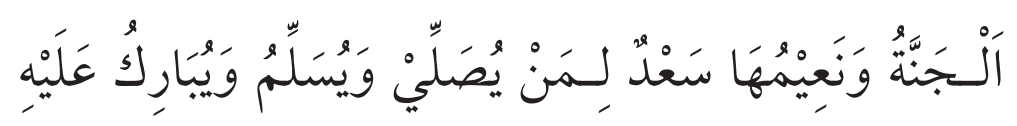

“Aljannatu Wa Na'iimuhaa Sa'dul Limay Yushallii Wa Yusallimu Wa Yubaariku' Alaihi".

9 Tarigan, Guntur. Prinsip-Prinsip Dasar Sastra. (Bandung: Angkasa, 1984), h. 126.

10 Ibid.

11 Ibid., h. 127. 
Artinya: Surga dan kenikmatannya sebagai keberuntungan bagi siapa saja yang bershalawat dan memohon selamat dan berkah atas Nabi.

Kemudian dilanjutkan dengan membaca;

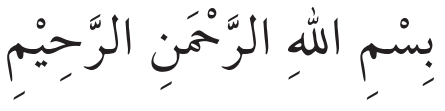

"Bismillahirrahmanirrahim".

Artinya: Dengan menyebut nama Allah Yang Maha Pengasih Lagi Maha Penyayang.

Bab I ayat 1 hal 6:

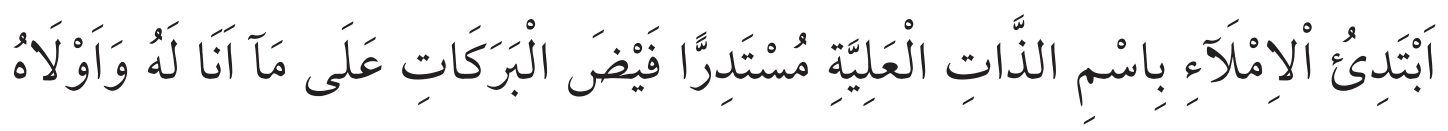

"Abtadi-Ul Imlaa-A Bismidzdzaatil 'Allyyah Mustadirran Faidlal Barakaati 'Alaa Maa Anaa Lahu Wa Aulaah".

Artinya: Saya mulai tulisan kitab (kitab Maulid Nabi) ini dengan menyebut nama Allah Yang Maha Agung, seraya memohon limpahan berkah atas apa yang telah diberikan-Nya.

Pada bab II hal 10, Pengarang yaitu Syekh Ja'far Al-Barzanji bershalawat dengan kalimat;

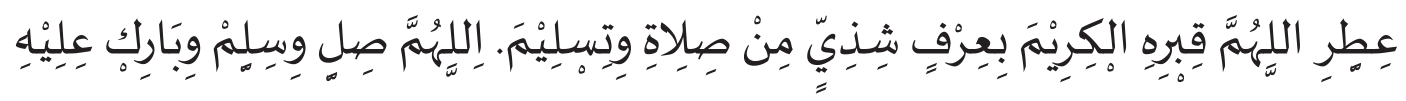

"Aththirillaahumma Qabrahul Kariima, Biarfin Syaziyyim Min Shalaatiw Wa Tasliim Allahumma Shalli Wasallim Wa Baarik'alaih".

Artinya: Semoga Allah mengharumkan dan mewangikan kuburnya (Nabi) yang mulia, dengan keharuman wangu-wangian salawat dan salam sejahtera. Ya Allah, berilah salawat dan salam serta berkah atas Nabi SAW.

Dalam eksposisi ini, Syekh Ja'far Al-Barzanji Husin bin Abdul Karimmemaparkan bahwa Nabi saw disebut juga Syaibatul Hamdi, yang terpuji budi pekertinya yang luhur. Kutipannya dapat dilihat pada BAB II ayat 1 halaman 10:

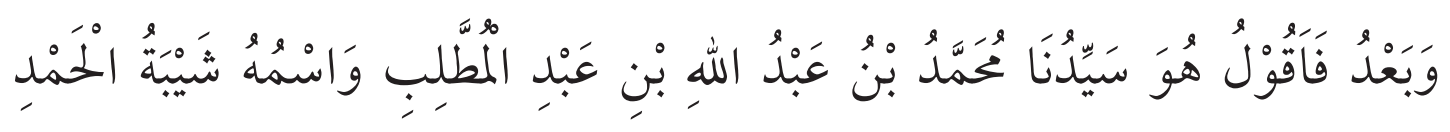




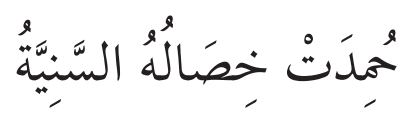

"Wa Ba'du Fa Aquulu Huwa Sayyiduna Muhammadubnu 'Abdillaahibni 'Abdil Muththalibi Wasmuhu Syaibatul Hamdil Humidat Khishaaluhus Saniyyah".

Artinya: Waba'du, maka saya katakana: Beliau adalah Muhammad bin Abdullah bin Abdul Muththalib, dan disebut juga dengan Syaibatul hamdi, yang terpuji budi pekertinya yang luhur.

b. Komplikasi

Bagian tengah atau komplikasipada bagian cerita bertugas mengembangkan konflik. Tokoh utama mengalami gangguan, halangan-halangan yang memisahkan serta menjauhkan dia dari tujuannya.Justru dalam komplikasi inilah para pembaca dapat mempelajari dan memahami bagaimanakah sebenarnya watak dari tokoh utama tersebut. ${ }^{12}$ Pengarang dapat menggunakan tekhnik sorot-balik atau flashbackuntuk memperkenalkan masa lalu tokoh utama itu kepada para pembaca, untuk menjelaskan situasi, ataupun memperlengkapi serta mempersiapkan motivasi bagi gerak serta tingkah laku tokoh utama.

Kutipan komplikasi dapat dilihat pada masa lalu tokoh utama yaitu Rasulullah yang telah dipaparkan pada Bab IV halaman 29;

Bab IV ayat 14 hal 29:

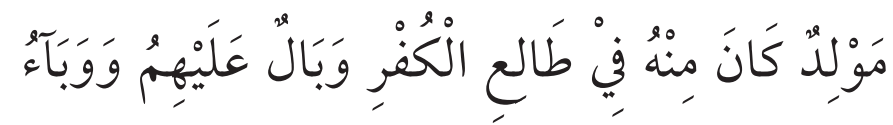

"Maulidun Kaana Minhu Fii Thaali-'Il Kufri Wa Baalun 'Alaihim Waw Abaa-U”

Artinya: Hari kelahiran beliau pada pandangan orang kafir merupakan suatu bencana dan malapetaka baginya.

Bab VI ayat 1 hal 35:

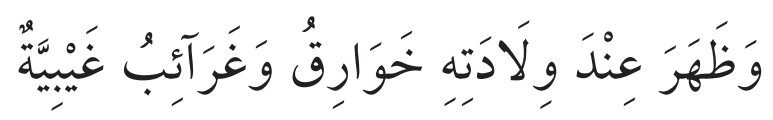

"Wa Zhahara 'Inda Wilaadatihi Khawaariqu Wa Gharaa-Ibu Ghaibyyah".

12 Ibid. 
Artinya: Pada waktu kelahiran Nabi Saw, terjadilah berbagai hal yang luar biasa, dan keanehan-keanehan bersifat ghaib.

c. Resolusi

Resolusi atau denouenment bagian akhir suatu cerita. Di sinilah sang pengarang memberikan pemecahan masalah dari semua peristiwa yang terjadi. Atau dengan kata lain denouement adalah "resolusi akhir dari komplikasi-komplikasi alur; sesuatu yang memberi pemecahan terhadap alur. Kadang-kadang, tetapi tidak selalu, resolusi ini bersamaan posisinya dengan klimaks". ${ }^{13}$

Kutipan resolusi dapat dilihat pada beberapa bagian yang terletak antara lain pada halaman 77 pada bab XII. Ini terkait dengan menjelang Beliau saw. menerima wahyu;

Bab XII ayat 6 hal 77:

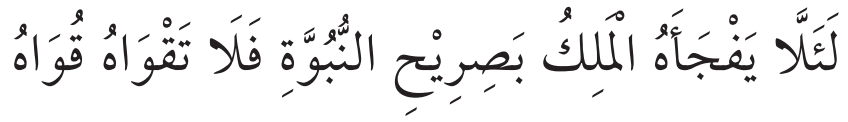

"Li-Alla Yafja-Ahul Malaku Bishariihin Nubuwwati Falaa Taqwaahu Quwaah".

Artinya: Agar tidak merasa gentar dan cukup mampu daya kekuatannya, manakala menghadapi malaikat Jibril as., yang akan menyampaikan wahyunya.

Bab XII ayat 7 hal 77:

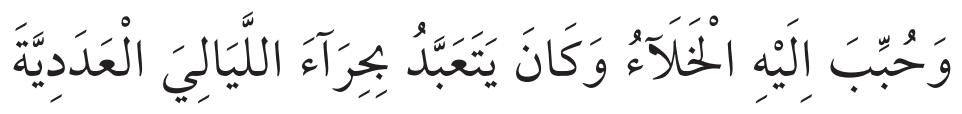

"Wahubbiba Ilaihil Khalaa-Ul Fakaana Yata 'Abbadu Bihiraa-Il Layaaliyal 'Adadiyyah"

Artinya: Dalam pada itu, Beliau saw. memang senang bersunyi diri, sedangkan tepat peribadatannya adalah Gua Hiro, sampai bermalam-malam lamanya.

\section{d. Klimaks}

Titik yang memisahkan komplikasi dengan resolusi disebut turning point atau klimaks.Justru pada klimaks inilah biasanya terdapat suatu perubahan penting atau crucial shiftdalam nasib, sukses atau tidaknya tokoh utama fiksi tersebut. Klimaks merupakan titik wilayah tempat melihat arah mana yang akan dituju oleh alur cerita tersebut.

13 Ibid. 
Kutipan klimaks dapat dilihat pada Bab XIII halaman 82, dimana terjadi suatu peristiwa penting dalam perjalanan Rasulullah saw. Isra Miraj.

Bab XIII ayat 1 hal 82:

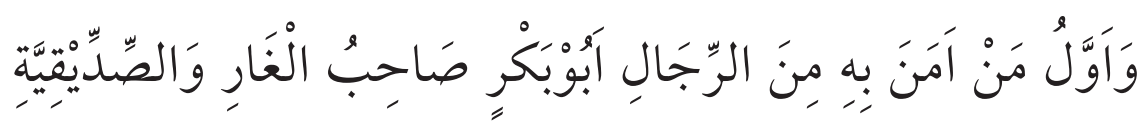

"Wa Awwalu Man Aamana Bihi Minarrijaali Abuu Bakrin Shaahibul Ghaari Washshid-Diiqiyyah."

Artinya: Orang lelaki pertama yang beriman kepada Nabi saw. adalah Abu Bakar Shiddiq, orang yang menemani Beliau ketika Tsur, ia digelari Assiddiq, karena merupakan orang pertama yang membenarkan peristiwa Isra.

\section{Setting (Latar)}

Latar adalah latar belakang fisik, unsur tempat dan ruang dalam suatu cerita. ${ }^{14}$

Beberapa kutipan yang terkait dengan tempat, waktu, peristiwa, suasana serta benda-benda dalam lingkungan tertentu, seperti;

\section{a. Qudla'ah}

Suatu tempat terpencil di Kota Makkah yang merupakan tujuan berkelana Beliau saw.tercantum pada bab II ayat 3 hal 11:

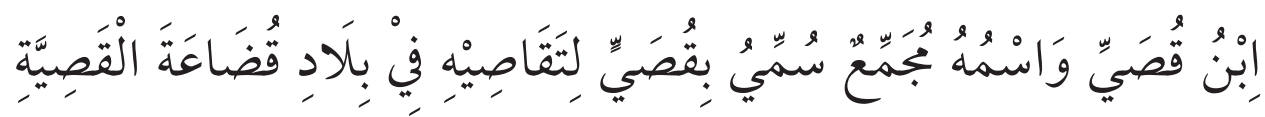

"Ibni Qushayyin Wasmuhuu Mujammi'un Summiya Biqusyayyin Litaqaashiihi Fii Bilaadi Qudlaa-'Atal Qashiyyah”.

Artinya: Bin Qushayyi danjuga dipanggil dengan Mujammi'. Dan dia disebut qushayyi, karena jauhnya berkelana di tanah Qudls'ah yang ter pencil di kota Makkah.

\section{b. Bilmadiinatil (Madinah)}

Suatu kota dimana ayahanda Beliau saw. wafat. Tercantum pada bab V ayat 2 hal 26:

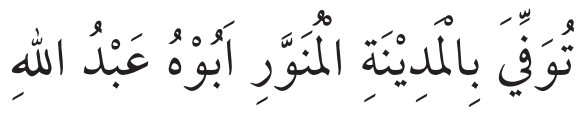

“Tuwuffiya Bilmadiinatil Munawarati Abuuhu 'Abdullah.

14 Ibid., h. 136. 
Artinya: Maka wafatlah ayahnya yang bernama Abdullah di kota Madinah.

c. Ka'Batal (Kakbah)

Adalah Baitullahdimana Nabi Muhammad saw. ketika masih bayi dibawa masuk kedalam $K a$ 'bah. Tercantum pada bab V ayat 5 dan 7 hal 33:

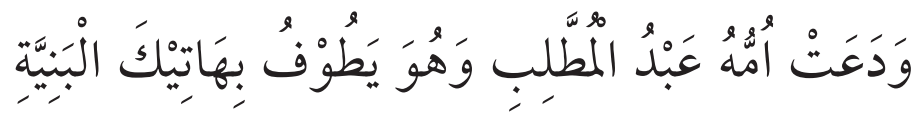

\section{“Wa Da'at Ummuhu, Abdal Muththlibi Wa Huwa Yathuufu Biha Tikal Baniyyah}

Artinya: Dan ibunya memanggil Abdul Muthalib, yang ketika itu sedang melakukan tawaf mengelilingi Ka'Bah.

\section{Character(Penokohan)}

Character (Penokohon) dan plot (alur) berhubungan sangat erat satu sama lainnya. Character adalah tokoh yang berperan dalam suatu cerita. ${ }^{15}$ Dengan kata lain: kalau sang pengarang berpikir mengenai tokoh, maka dia takkan dapat memikirkan tokoh tersebut.

Adapun menurut ada lima cara menyajikan watak tokoh, yaitu:Melalui apa yang diperbuatnya, tindakan-tindakannya, terutama bagaimana ia bersikap dalam situasi kritis, mengetahui apakah tokoh tersebut orang tua, orang berpendidikan, wanita atau pria, kasar atau halus, penggambaran fisik tokoh, melalui pikiran-pikirannya. ${ }^{16}$

Character dapat diketahui melalui tindakan-tindakannya, ucapan-ucapannya, penggambaran fisik, dan melalui pikirannya. Ada beberapa penggambaran yang dikutip pada ayat di bawah ini:

\section{a. Abdullah.}

Ayahanda Nabi Muhammad saw. Kutipan tersebut pada bab II ayat 1 hal 10 dan bab IV ayat 2 hal 26:

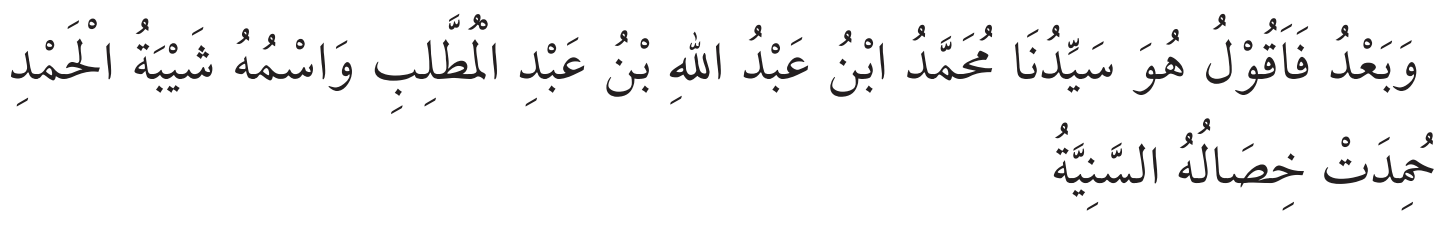

"Wa Ba'du Fa Quulu Huwa Sayyiduna Muhammadubnu Abdilaahibni 'Abdil Muththalibi Wasmuhu Syaibatul Hamdi Humidat Khishaaluhus Saniyaah".

15 Ibid., h. 148.

16 Soemardjo, Jakob dan Saini. Apresiasi Sastra. (Jakarta: Gramedia Pustaka Utama, 1986), h. 65 
Artinya: Waba'du, maka saya katakan: Beliau adalah Muhammad bin Abdullah bin Abdul Muthalib, dan disebut orang juga dengan Syaibatul Hamdi, yang terpuji budi pekertinya yang luhur.

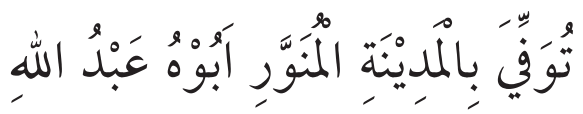

\section{“Tuwuffiya Bilmadiinatil Munawwarati Abuuhu 'Abdullaah"}

Artinya: Maka wafatlah ayahnya( Ayahnya Nabi Muhammad saw.) yang bernama Abdullah di kota Madinah.

b. Aminah.

Ibunda Nabi Muhammad saw.yang merupakan pilihan Allah Ta'ala. Kutipan tersebut terdapat pada bab III ayat 3 dan 4 hal 20:

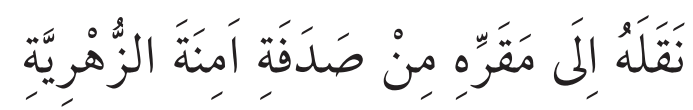

“Naqalahu Ilaa Maqarrihi Min Shadafati Aaminataz Zuhriyyah"

Artinya: Maka Allah Ta'ala memindahkan nur tersebut kepada Aminah yang suci.

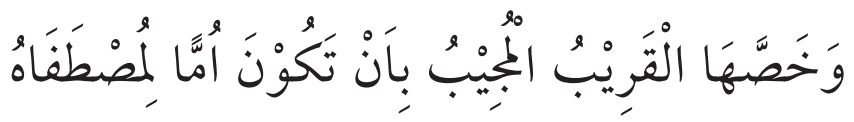

“Wa Khashshahal Qariibul Mujiibu Bi Antakuuna Umma Limushthafaah".

Artinya: Dan Allah Swt mengkhususkan kepadanya, sebagai ibu dari Nabi yang terpilih.

c. Nabi Muhammad SAW.

Beliau adalah sebagai Nabi dan Rasul yang diistimewakan Allah Ta'ala dan diberi anugrah dengan sifat-sifat utama.Kutipan tersebut dapat lihat pada bab II ayat 15 hal 15, ayat19, hal 17:

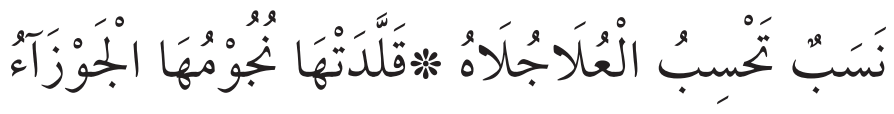

“Nasabun Tahsibul 'Ulaa Bihulaahu Qalladathaa Nujuumuhal Jauzaa-U”.

Artinya: Nasab Beliau saw. terhitung nasab mulia, bagaikan sekumpulan bintang kejora. 


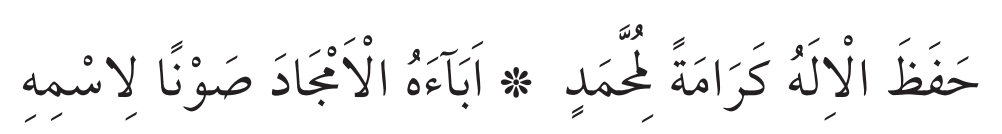

"Hafizhal Ilaahu Karaamatal Limuham-Madin Aabaa-Ahul Amjaada Shaunan Lismihi".

Artinya: Tuhan (Allah Ta'ala) telah memelihara kemuliaan Nabi Muhammad saw. terhadap bapak-bapaknya yang mulia, demi memelihara namanya.

\section{Theme (Tema)}

Theme (Tema) merupakan bagian yang penting dalam dalam seluruh cerita. Suatu cerita yang tidak memiliki tema tentu tidak ada artinya. Walaupun misalnya pengarang tidak menjelaskanapa tema ceritanya secara eksplisit, hal itu harus dapat dirasakan dan disimpulkan oleh para pembaca setelah selesai membaca.

Tema juga hal yang paling utama dilihat oleh para pembaca sebuah tulisan. Jika temanya menarik, maka akan memberikan nilai lebih pada tulisan tersebut. Theme (Tema) dalam naskah Barzanji adalah menceritakan "Riwayat kehidupan Nabi Muhammad SAW terutama dalam bentuk peristiwa kelahirannya, masa kanak-kanak hingga diangkat menjadi Rasul, silsilah keturunannya, sifat mulia yang dimilikinya, dan berbagai peristiwa yang dapat menjadi tauladan umat Islam".

Dari ulasan singkat dapat dilihat dalam kutipan berikut ini;

Bab II ayat 15 hal 15:

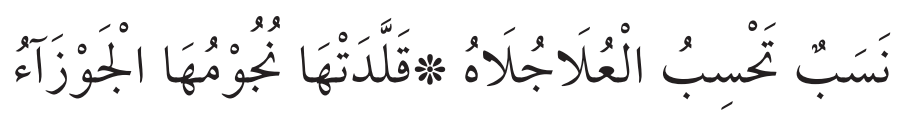

"Nasabun Tahsibul 'Ulaa Bihulaahu Qalladathaa Nujuumuhal Jauzaa-U”.

Artinya: Nasab Beliau saw. terhitung nasab mulia, bagaikan sekumpulan bintang kejora.

Bab XI ayat 2 hal 76:

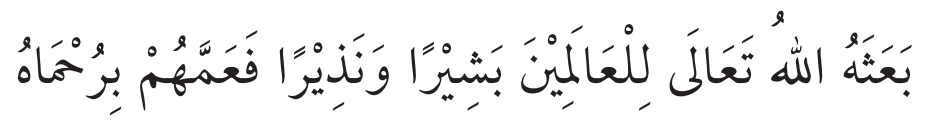

“Ba-'Atsahullahu Ta'aalaa Lil 'Aalamina Basyiiran Wa Nadziiran Fa-'Ammahum Biruhmaah".

Artinya: Maka Allah Ta'ala mengangkat Beliau menjadi Rasul-Nya sebagai pembawa berita gembira dan pembawa peringatan, dengan maksud untuk umat seluruh alam. 


\section{Point of View (Sudut Pandang).}

Menurut S Tasrif Point of View (Sudut pandang) merupakan hubungan antara penulis dalam menyampaikan ceritanya ataupun dengan pikiran dan perasaan pembacanya bahwa dia selaku narrator atau pencerita. ${ }^{17}$

Menurut Tarigan ada tiga bagian penting dalam Point of View (Sudut pandang), yaitu: ${ }^{18}$

(1) The Omniscient View; Seorang narrator mengetahui segala sesuatunya, bahkan pikiran dan perasaan dari para pelakunya, dan dapat melihat tingkah laku mereka dari segala sudut.

(2) The First PersonPoint of View; Cerita itu dapat diceritakan oleh seorang tokoh. Narrator dapat pula dari salah seorang tokoh-tokoh utama atau orang lain.

(3) The Third PersonPoint of View; seorang di luar cerita itu bertindak sebagai tukang cerita atau narrator.

(4) The Central intetelligence; cerita itu disajikan seperti yang terlihat melalui mata salah seorang pelaku, walaupun ada hubungannya dengan yang dilakukan oleh Omniscientnarrator.

(5) The Scenic; narrator disingkirkan dan cerita itu disajikan hampir seluruhnya dalam percakapan atau dialog, seperti yang biasa dapat dalam drama. (Morris [et al], 1964:347).

Point of View (Sudut pandang)dari naskah "Barzanji” tersebut adalah termasuk dalam The Third PersonPoint of View; seorang di luar cerita itu bertindak sebagai tukang cerita atau narrator. Kutipannya dapat dilihat pada Bab I ayat 1, 2, 3, 4 hal 6 dan ayat 9,10 hal 8 :

Ayat 1 hal 6:

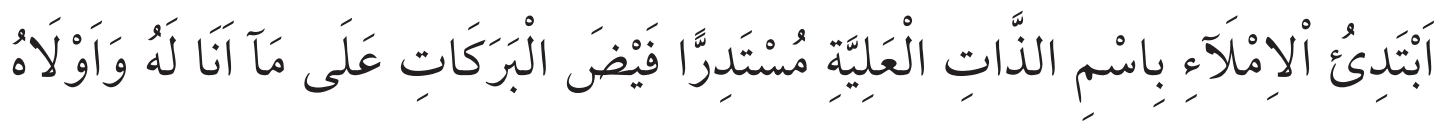

"Abtadi-Ul Imla-A Bismidzdzaatil 'Aliyyah. Mustadirran Faidlal Faidlal Barakaati 'Alaa Maa Anaa Lahu Wa Aulaah".

Artinya: Mulai penulisan kitab (kisah Maulid Nabi) ini dengan menyebut nama Allah Yang Maha Agung, seraya memohon limpahan berkah atas apa yangtelah diberikanNya.

17 Tarigan, Guntur. Prinsip-Prinsip Dasar Sastra, h. 140.

18 Ibid. 
Ayat 2 hal 6:

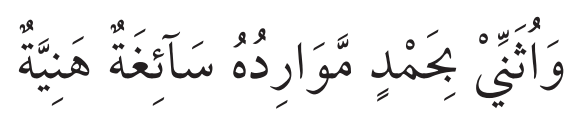

"Wa Utsannii Bihamdim Mawaariduhu Saa-Ighatun Haniyyah".

Artinya: Dan juga saya memanjatkan puja dan puji, dengan pujian yang taka da henti-hentinya.

Ayat 4 hal 6:

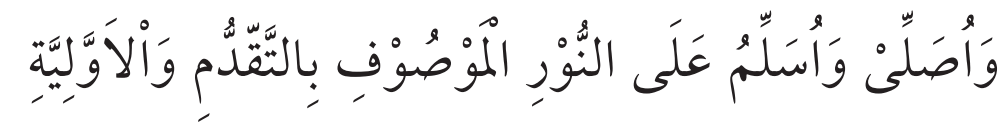

"Wa Ushallii Wa Usallimu 'Alan Nuuril Maushuufi Bittaqaddumi Wal Awwaliyyah".

Artinya: Dan saya mengucapkan salawat dan salam atas "Nur" (Muhammad) yang bersifat mendahului dan mengawali.

\section{Style (Gaya)}

Gaya bahasa berhubungan dengan pemanfaatan figurative language. Gaya penulisan berkaitan dengan gaya ( kebiasaan ) menulis. Menurut Soemardjo dan Saini ( 1986 : 92 ) gaya adalah cara khas pengungkapan pengarang, cara memilih tema, dan menceritakannya dalam sebuah cerita.Figurative language ada bermacam-macam, namun mempunyai suatu hal yang umum, yaitu memperhatikan sesuatu dengan cara menghubungkannya dengan sesuatu yang lain. ${ }^{19}$ Jenis-jenis bahasa kiasan adalah (a) simile, (b) metafora, (c) hiperbola, (c) repetisme, (d) paralelisme, (e) sarkasme. Pada bagian style ini akan dipaparkan beberapa gaya bahasa sebagai bentuk perwakilan yang lainnya. Sebab tidak semua unsur gaya bahasa terdapat pada naskah tersebut. Yang ditampilkan antara lain;

a. Smile (Perbandingan)

Smile adalah gaya bahasa yang menyamakan satu hal dengan hal lain dengan menggunakan kata-kata pembanding, seperti bagai, sebagai, bak, seperti, semisal, seumpama, se-, dan kata-kata pembanding yang lain. Kutipannya tercantum pada bab II hal 16:

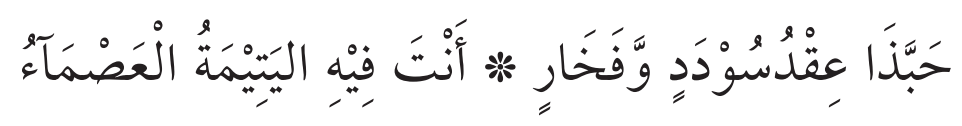

19 Soemardjo. Apresiasi Sastra, h. 92. 
“Habbadzaa 'Iqdu Suudadin Wa Fakhaarin Anta Fiihil Yatiimatul 'Shmaa-U”.

Artinya: Ibarat kalung mutiara hiasanmegah, di dalamnya, engakau sangat berharga dan terpelihara.

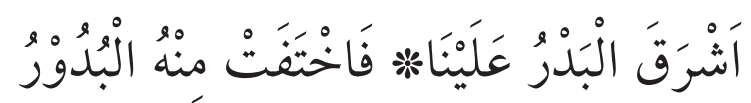

"Asyraqal Badru 'Alaina. Fakhtafat Minhul Buduru"

Artinya: 'Telah terbit bulan purnama atas kita'. 'Maka tersembunyilah dari padanya semua bintang'

\section{Atmosphere (Suasana)}

Cerita yang menarik hati harus hidup.Pembaca harus merasai bersama-sama dengan pelakon segala kejadian yang dialaminya. Menurut Brooks dan Warren atmosphere adalah perasaan umum yang memancar yang ditimbulkan oleh faktorfaktor yang beraneka ragam dalam suatu cerita, seperti latar, tokoh, tema, dan sebagaianya, efek dari penyajian atau penggarapan itu secara keseluruhan. ${ }^{20}$

Atmosphere (Suasana) yang akan dideskripdikan disini adalah tatkala Beliau saw. diangkat menjadi Rasul-Nya. Beberapa peristiwa penting yang menjadi pelajaran umat seluruh alam. Bagian ini dapat dilihat pada kutipan bab XII ayat 2, 3, 4, 5, 6, 7, 8,9 hal 76 sampai 78 ;

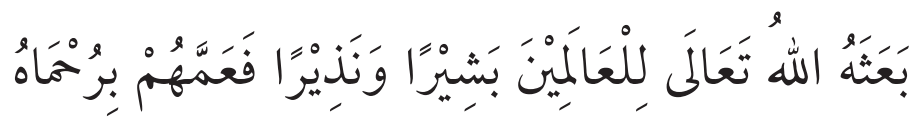

"Ba-'Atsahullahu Ta'aalaa Lil 'Aalamiina Basyiiran Wa Nadziiran Fa-'Ammahum Biruhmaah".(ayat 2 hal 76).

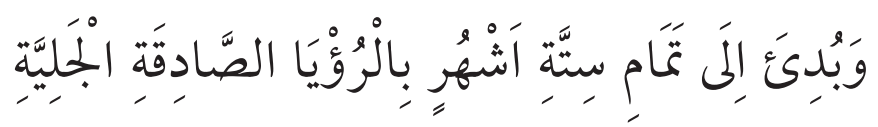

"Wa Budi-A Ilaa Tamaami Sittati Asyhurin Birru'yash Shaadiqatil Jaliyyah". (ayat 3 hal 76).

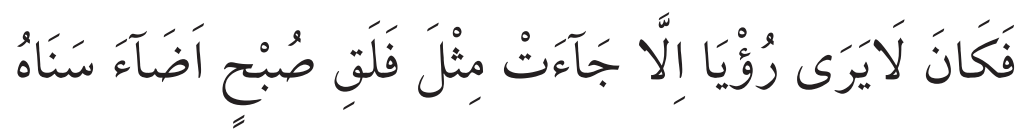

“Fakaana Laa Yaraa Ru'yan Illaa Jaa-At Mitsla Falaqi Shubhin Adlaa-A Sanaah". (ayat 4 hal 76).

20 Tarigan, Guntur. Prinsip-Prinsip Dasar Sastra, h. 135. 


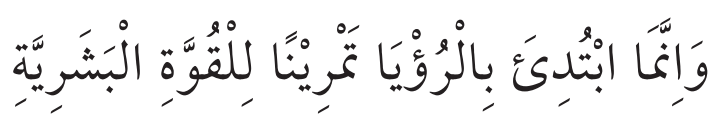

“Wa Innamabtudi-A Birru'yaa Tamriinan Lil Quwwatil Basyariyyah"(ayat 5 hal 77).

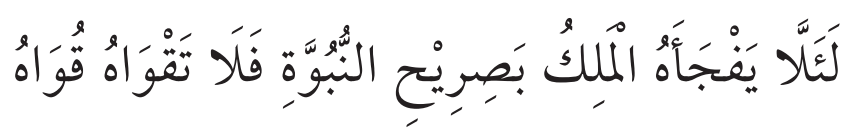

"Li-Alla Yafja-Ahul Malaku Bishariihin Nubuwwati Falaa Taqwaahu Quwaah". (ayat 6 hal 77).

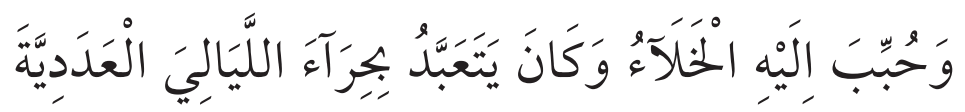

"Wahubbiba Ilaihil Khalaa-Ul Fakaana Yata 'Abbadu Bihiraa-Il Layaaliyal "Adadiyyah" (ayat 7 hal 77).

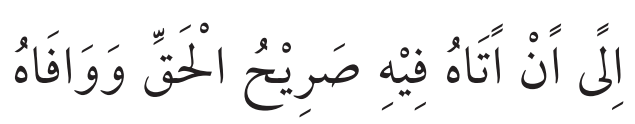

“Ilaa An Ataahu Fiihi Shariihul Haqqi Wawaafaah".(ayat 8 hal 78).

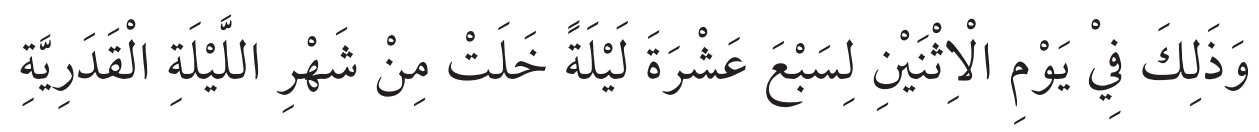

“Wa Dzaalika Fii Yaumil Itsnaini Lisab' A'asyrata Lailatan Khalat Min Syahril Lailatil Qadriyyah".(ayat 9 hal 78).

Artinya: Maka Allah Ta'ala mengangkat Beliau menjadi Rasul-Nya sebagai pembawa berita gembira dan pembawa peringatan, dengan maksud untu umat seluruh alam (ayat 2).

Pada enam bulan pertama, Beliau mendapat impian-impian yang benar dan nyata (ayat 3). Setiap kali Beliau bermimpi, Beliau melihat seola-olah ada sinar pagi yang memancar cemerlang membelah kegelapan di ufuk timur (ayat 4). Sesungguhnya pada waktu menjelang pengangkatannya itu dimulai impian-impian, dimaksudkan untuk menggembleng jiwa insaninya, agar beliau mempunyai dasar yang kokoh dan kuat (ayat 5). Agar tidak merasa gentar dan cukup mampu daya kekuatannya, manakala menghadapi malaikat Jibril as., yang akan menyampaikan wahyunya (ayat 6). Dalam pada itu, Beliau saw. memang senang bersunyi diri, sedangkan tepat peribadatannya adalah Gua Hiro, sampai bermalam-malam lamanya (ayat 7). Hingga datang malaikat Jibril menyampaikan wahyu (ayat 8). Ketika itu pertepatan pada hari Senin tanggal 17 Ramadhan (ayat 9). 


\section{PerspektifPondok Pesantren Ittihadil Ummah terhadap Barzanji}

Pérspéktif adalah cara pandang seseorang terkait dengan suatu hal atau masalah tertentu. (dikutip hari sabtu, 20-08-2016 dari internet: http:/ / kbbi.web.id/perspektif). Menurut salah satu tokoh pemuda di pondok pesantren tersebut (hasil wawancara) yaitu Fahrurrozi, S.Pdbahwatradisimembaca naskah barzanji di Pondok Pesantren Ittihadil Ummah tidak hanya dilakukan sebagai kegiatan rutin, namun dilakukan di berbagai kesempatan misalnya pada saat kelahiran bayi, mencukur rambut bayi (aqiqah), acara khitanan, pernikahan, dan upacara lainnya. Dalam kegiatan keagamaan di masjid-masjid perkampungan, biasanya jamaah duduk bersimpuh melingkar. Lalu seseorang membacakan barzanji, dan jemaah lainnya mengikuti secara bersamaan.

Selanjutnya menurut TGH.Tanwir Izhar (Pengurus Ponpes Ittihadil Ummah Karang Anyar Mataram), membaca naskah Barjanzi memiliki beberapa macam nilai positif di antaranya;

1. Nilai Agama.

Membaca naskah Barzanjidapat memberikan suatu kecintaan terhadap Rasulullah SAW.dimana lantunan syairnya memiliki nilai agamis sehingga dapat dijadikan sebagai pelajaran bagi diri kita dalam kehidupan sehari-hari.

2. Nilai Sosial.

Membaca naskah Barzanjidapat membangun silaturahim bagi masyarakat karena membaca Barzanjisering digelar pada perayaan hari besar Maulid Nabi dan berbagai acara lainnya, seperti cukur rambut bayi, perkawinan, kelahiran anak, khitanan, dan mempererat persaudaraan.

Lantunan "Barzanji" umumnya dibacakan dalam sebuah momentum tertentu bagi umat Islam seperti yang telah dipaparkan sebelumnya, tentunya ini bukan merupakan suatu kewajiban karena tidak ada dasar ataupun keterangan yang mengharuskan. Dari segi prinsip dan tujuan sangat baik, yaitu memberi penghargaan kepada Rasulullah SAW dengan cara membacakan riwayat hidupnya. Dan kita sebagai generasi muda tidak hanya sekedar membacanya namun perlu lebih diperdalam maknanya dan kita dapat mengambil pelajaran yang sangat berharga dari peri kehidupan beliau.

\section{PENUTUP}

\section{Kesimpulan}

Pada hakekatnya naskah Barzanjiadalah aktivitasmembaca riwayat Nabi Muhammad SAW. Kitab ini merupakan suatu karya sastra karena lebih menampakkansegi keindahan bahasa. Kitab ini ada dua macam yang satu dalam bentuk prosa dan lainnya dalam bentuk puisi. Isinya sama-sama menceritakan 
riwayat hidup Nabi Muhammad SAW terutama dalam bentuk peristiwa kelahirannya. Prosa dan puisi tentang riwayat Rasulullah SAW ini sering di dibacakan dalam banyak peristiwa seperti maulid Nabi bahkan dalam perayaan lainnya.

KitabBarzanji dikarang oleh Syekh Ja'far Al-Barzanji Husin bin Abdul Karim lahir di Madinah tahun 1690 dan wafat pada tahun 1766. Al-Berzanji berasal dari sebuah daerah di Kurdistan, Barzini. Nama asli kitab karangan yang kemudian lebih dikenal dengan nama Al-Berzanji adalah 'Iqd al-Jawahir yang berarti "Kalung Permata".

Selain daripada itu, penelitian ini mengarah pada analisis unsur intrinsik; plot, setting, character, theme, point of view, styledan atmosphere dan Perspektif Pondok Pesanteren Ittihadil Ummah, Karang Anyar, yang terkait dengan karya sastra yang mengacu pada kitab BarzanjiKarya Ja'fa Al Barzanji (Kitab diterjemahkan oleh Abu Ahmad Nadjieh) di terbitkan oleh Mutiara Ilmu Surabaya, Cetakan Pertama, Maret 2009/ Rabiul Awal 1430 H.

\section{Saran}

Mengingat membaca kitab Barzanji sangat berharga, maka harus tetap dilestarikan oleh generasi selanjutnya dengan cara pengembangan, dokumenasi, serta diperlukan penelitian lebih lanjut. Selain daripada itu, bagi masyarakat, membaca Barzanjiterus dibaca tidak saja pada perayaan keagamaan tetapi juga menambah wawasan atau pengetahuanterkait dengan nilai-nilai religius, sosial, dan lainnya. 


\section{DAFTAR PUSTAKA}

Al-Andalasi, As'ad Al-Tabi'in. 2014. Sejarah al-Barzanji dan Perkembangannya. (Dikutip di internet hari Senin tanggal 7 Maret 2016, a2dcollection.blogspot. co.id/2014/12/ sejarah-al-barzanji-dan-perubahannya.HTML)

Hutomo, Suripan Sadi. 1991. Mutiara yang Terlupakan. Pengantar Studi Sastra Lisan. Hiski, Jawa Timur.

Nadjieh, Abu Ahmad. 2009. Terjemah Maulid al-Barzanji. Surabaya: Mutiara Ilmu.

Sherzer, Joel. 1979. Explaination in Ethnography of Speaking. Cambridge University.

Soemardjo, Jakob dan Saini. 1986. Apresiasi Sastra. Jakarta: Gramedia Pustaka Utama.

Tarigan, Guntur. 1984. Prinsip-Prinsip Dasar Sastra. Bandung: Angkasa.

Teeuw. A. 1984. Sebuah Pengantar Sastra dan Ilmu Sastra. Jakarta: Dunia Pustaka Jaya. 